DOI: 10.1002/ ((please add manuscript number))

Article type: Full Paper

\title{
Probing Film Solidification Dynamics in Polymer Photovoltaics
}

\section{Jeff L. Hernandez, Elsa Reichmanis and John R. Reynolds*}

Jeff L. Hernandez, Prof. J. R. Reynolds

School of Chemistry and Biochemistry

School of Materials Science and Engineering

Center for Organic Photonics and Electronics (COPE)

Georgia Institute of Technology

Atlanta, GA 30332-0400, USA

E-mail: reynolds@chemistry.gatech.edu

Prof. Elsa Reichmanis,

School of Chemical and Biomolecular Engineering, School of Chemistry and Biochemistry, School of Materials Science and Engineering, Brook Byers Professor of Sustainability, Georgia Institute of Technology, Atlanta, Georgia 30332-0100, United States

Keywords: Blade coating, inverted solar cell, organic photovoltaics, P3HT, PCBM

\begin{abstract}
:
Semiconducting conjugated polymers have drawn a great deal of attention over the past decade due to their solution processability and potential use in roll to roll fabrication of organic solar cells. Here, we report the effect of solvent vapor pressure on poly(3hexylthiophene):[6,6]-phenyl C61-butyric acid methyl ester (P3HT:PCBM) blade coated inverted solar cells using $\mathrm{ZnO}$ as the electron transporting layer and $\mathrm{MoO}_{3}$ as the hole transporting layer. The resultant morphology and device performance are investigated for devices processed from solvents with varied vapor pressure and a mixed solvent. We report that the use of a mixed solvent system is advantageous for controlling the initial vapor pressure of the processing solution, thereby controlling the phase separated morphology between P3HT and PCBM which impacts ultimate solar cell performance.
\end{abstract}




\section{Introduction}

As reported by the U.S. Energy Information Administration, world energy consumption is expected to grow $56 \%$ from 2010 to 2040 . The fastest growing segments of the energy market are renewables and nuclear, which are expected to increase by $2.5 \%$ per year. ${ }^{[1]}$ As the global demand for energy increases, new, innovative ways to meet those demands in a cost effective, sustainable manner are essential and imperative. Further, technologies having a low carbon footprint are desirable. One attractive, emerging renewable energy technology that offers the potential to meet all the desired attributes is broadly represented by solar, organic and hybrid photovoltaics (OPVs) in particular. OPV utilizes highly tunable materials; single junction devices based upon small molecules have achieved efficiencies approaching $9 \%,{ }^{[2,3]}$ while polymeric materials have afforded cells with power conversion efficiencies (PCEs) higher than $9 \% \cdot \cdot^{[4,5]}$

Substantial efforts have been focused towards materials design and synthesis to produce novel small molecule and polymeric materials that will yield devices with optimized performance attributes, power conversion efficiency (PCE) in particular. ${ }^{[6]}$ However, until recently, a quantitative understanding of how materials processing impacts device characteristics has lagged behind efforts to identify alternative molecular structures. While the design and synthesis of materials that afford high PCE's and demonstrate good stability is important, the ability to process those materials into integrated large-scale OPV systems, while maintaining optimum device performance, may well be the defining element to the success of OPV technology. ${ }^{[7]}$

The most readily available laboratory-based process methodology used in the fabrication of thin polymer films is spin coating, and this technique is the one most commonly used to fabricate OPV devices in a research environment. However, spin coating is not viable for 
either the manufacture of large-area or flexible devices. Further, and perhaps more importantly, the critical process parameters that control thin-film morphology will be substantially different for films prepared via spin coating vs. alternative methods such as spray coating, ${ }^{[8,9]}$ slot die coating, ${ }^{[10]}$ ink jet printing, ${ }^{[11]}$ and blade coating, ${ }^{[12-21]}$ which makes it critical to investigate these various large scale processing techniques. While the final morphology and its evolution during spin coated film formation has been extensively studied, investigations associated with blade coating have lagged behind, even though it is especially well-suited for ultimate comparison to roll-to-roll (RtR) manufacturing processes. ${ }^{[2,23]}$ The impact of the active layer deposition process is aptly demonstrated in a report by Brabec et al. who showed that the thin-film morphology obtained upon blade $v s$. spin coating active layer thin-films is markedly different, with blade coating affording higher open circuit voltage $\left(\mathrm{V}_{\mathrm{oc}}\right) \cdot{ }^{[13]}$

An additional principal consideration related to OPV device fabrication pertains to the ability to integrate the active layer thin-film deposition method with low-cost, high throughput, large-area fabrication via RtR production. While solution processed OPV's can be realized using RtR methods, to be commercially viable, a sound knowledge base regarding critical process parameters associated with RtR compatible solution processed materials for solar cell devices is an imperative, as is knowledge concerning the impact and control of resultant morphology. Fundamentally then, we ask "How do we bridge the processing gap?", and move away from spin coating to RtR compatible processing methods for large area high efficiency OPVs?

Here, blade coating was used to fabricate the active layer of inverted solar cells from a solution of poly(3-hexylthiophene-2,5-diyl) and [6,6]-phenyl $\mathrm{C}_{61}$ butyric acid methyl ester(P3HT/PC $\left.{ }_{60} \mathrm{BM}\right)$ to identify and investigate the critical process parameters associated with the fabrication of OPVs via blade coating of the active layer. A series of common chlorinated processing solvents, which have a difference in vapor pressure over a range of 
three orders of magnitude, were selected to examine solvent effects, such as evaporation rate, on ultimate morphology and device performance. Solvents such as chlorobenzene, orthodichlorobenzne and toluene are commonplace in OPV fabrication, ${ }^{[14-17]}$ however, their impact on the performance of blade coated devices has not been investigated. Since the kinetic and thermodynamic phenomena associated with blade coating will differ substantially from the largely kinetically driven processes operational during spin coating, it is essential to elucidate the role of the solvent in the former approach to OPV device fabrication. ${ }^{[24]}$

Bulk-heterojunction inverted solar cells were fabricated using P3HT (>98\% head to tail) and $\mathrm{PC}_{60} \mathrm{BM}$ in anhydrous chloroform $(\mathrm{CF})$, chlorobenzene $(\mathrm{CB})$, ortho-dichlorobenzne (DCB) and trichlorobenzene (TCB) as the deposition solvent. All four systems exhibit significant vapor pressure differences of approximately one order of magnitude between each solvent at room temperature, which facilitates investigation of the effects of deposition solvent characteristics, solvent vapor pressure in particular, on active layer thin-film morphology and ultimately device performance.

\section{Results and Discussion}

\subsection{Solvent Analysis}

The physical characteristics of the four solvents $(\mathrm{CF}, \mathrm{CB}, \mathrm{DCB}, \mathrm{TCB})$ used in this investigation are shown in Table 1. The solvents were selected based upon wide differences in vapor pressure and boiling point: the former ranges from a high of just over $190 \mathrm{mmHg}$ to a low of approximately $0.3 \mathrm{mmHg}$ for $\mathrm{CF}$ and $\mathrm{TCB}$, respectively, while boiling point spans from 61 to $214{ }^{\circ} \mathrm{C}$. The boiling point and vapor pressure differences will affect blade coated thin-film drying time, which in turn will impact both the morphology and device characteristics, thereby facilitating correlation of device properties with process solvent attributes. It is hypothesized that an increase in drying time through the use of low vapor pressure solvent, will allow for development of an optimum nanoscale phase morphology and will correlate with high device efficiencies. 
The inherent solubility characteristics of a deposition solvent may also be expected to affect the film deposition process. One measure of solubility derives from the Hansen solubility parameters (HSP), which provide insight into polymer/solvent mixing through calculated thermodynamic characteristics of the media. As seen from the data in Table 1, P3HT:PC ${ }_{60} \mathrm{BM}$ solubilizes well in the four chlorinated solvents under investigation. ${ }^{[25]}$ While HSP analysis can be a useful tool to evaluate the solubility of specific components and impacts ink formulations, kinetic factors play a large and influential role, thereby ultimately regulating morphology and device performance. ${ }^{[26]}$ Factors such as vapor pressure and/or boiling point will bear directly on the kinetics of film formation.

Table 1. Characteristics of solvents investigated for blade coating P3HT:PCBM thin films: properties that influence polymer-solvent interactions and drying kinetics in polymer solutions and films.

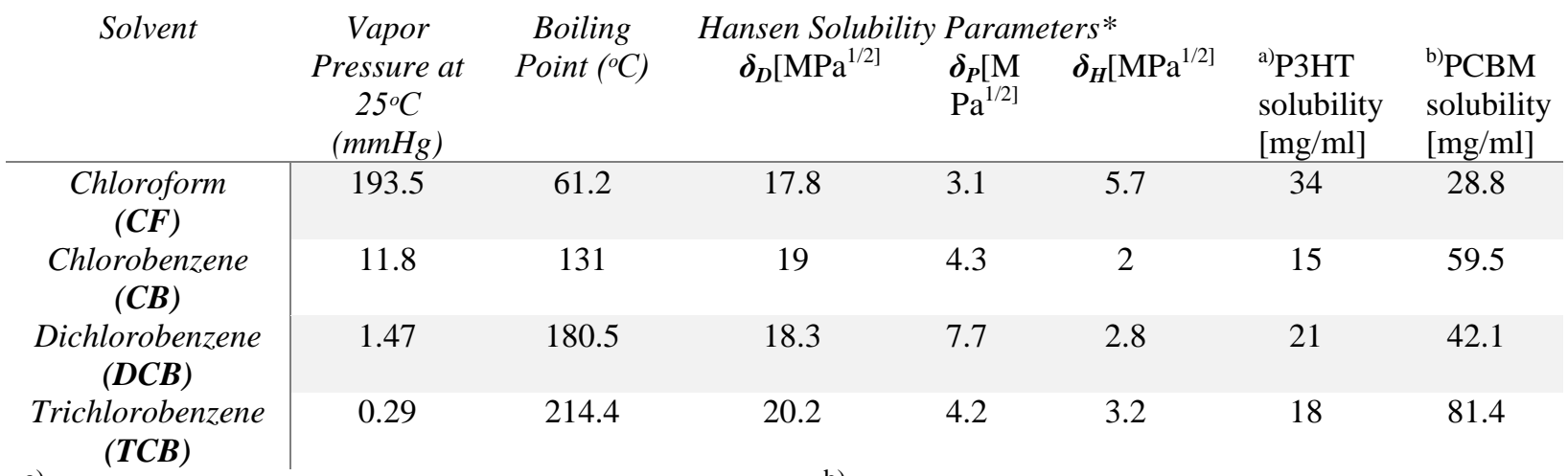

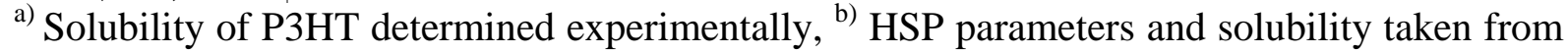
reference [25].

\subsection{Blade coated P3HT:PCBM Solar Cell Characteristics}

Figure 1 and Table 2 show the current density $\left(\mathrm{mA} / \mathrm{cm}^{2}\right)$ vs. voltage (V) (J-V) characteristics of inverted solar cells fabricated via blade coating the active layer under ambient atmosphere. In this study, inverted solar cells were fabricated starting with cleaned indium tin oxide (ITO) substrates onto which $\mathrm{ZnO}$ sol-gel was spin coated and annealed in air to form a semi-transparent electron transporting layer. $\mathrm{P} 3 \mathrm{HT}: \mathrm{PC}_{60} \mathrm{BM}$ was blade coated onto the $\mathrm{ZnO}$ layer in air and allowed to dry. Devices were then brought into a glovebox where they were thermally annealed at $140^{\circ} \mathrm{C}$ for 35 minutes followed by thermal evaporation of 4 
$\mathrm{nm}$ of $\mathrm{MoO}_{3}$, which serves as a hole-transporting layer, and $100 \mathrm{~nm}$ of Ag. The inverted architecture was used due to the higher air stability of inverted devices vs. conventional structures brought by the higher work function a $\mathrm{Ag}(4.73 \mathrm{eV})$ electrode relative to $\mathrm{Ca}(2.9 \mathrm{eV})$ and $\mathrm{Al}$ (4.08). Electrons are collected at the ITO interface while holes are collected at the Ag electrode. Incorporating this geometry also circumvents using poly(3,4ethylenedioxythiophene):poly(styrenesulfonate) (PEDOT:PSS) on ITO which is reported to hinder device performance due to chemical instabilities at the interface. ${ }^{[27]}$ Average solar cell characteristics were determined in order to more accurately represent the experimental data, ${ }^{[28]}$ with typically 8 devices tested for each set of conditions.
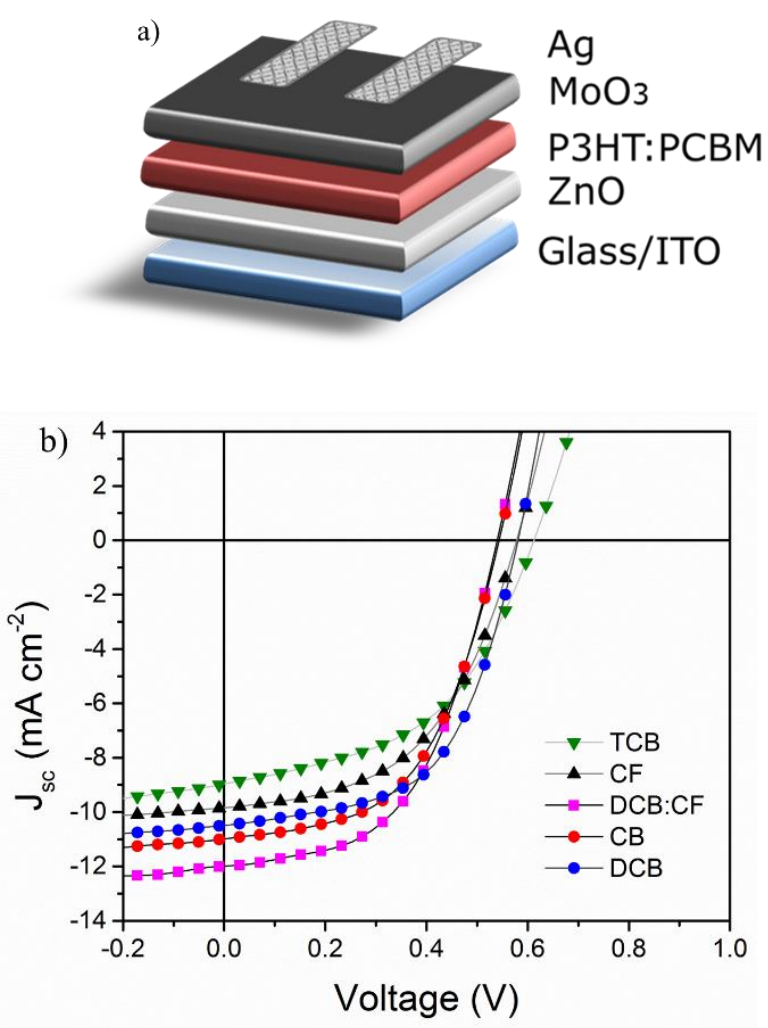

Figure 1. (a) Schematic of inverted organic solar cell, (b) J-V characteristics of P3HT:PCBM blade coated inverted solar cells as a function of processing solvent. 
Table 2. J-V characteristics of blade coated P3HT:PCBM solar cells. The values in parentheses are for the best performing device.

\begin{tabular}{c|cccccc} 
Solvent & $J_{S C}\left(\mathrm{~mA} / \mathrm{cm}^{2}\right)$ & $V_{O C}$ & $F F \%$ & $P C E \%$ & $\mu_{H}\left(\mathrm{~cm}^{2} \mathrm{~V}^{-1} \mathrm{~s}^{-1}\right)$ & $W(\mathrm{meV})$ \\
\hline $\boldsymbol{C F}$ & $9.66 \pm 0.24$ & 0.58 & $48.38 \pm 3.14$ & $2.69 \pm 0.18$ & $2.4 \times 10^{-6}$ & 202 \\
& $(9.87)$ & $(0.58)$ & $(50.52)$ & $(2.87)$ & & \\
$\boldsymbol{C B}$ & $11.29 \pm 0.6$ & 0.54 & $52.11 \pm 2.47$ & $3.16 \pm 0.09$ & $1.2 \times 10^{-5}$ & 169 \\
& $(11.52)$ & $(0.54)$ & $(53.72)$ & $(3.31)$ & & \\
$\boldsymbol{D C B}$ & $10.52 \pm 0.31$ & 0.57 & $53.23 \pm 2.57$ & $3.18 \pm 0.12$ & $3.0 \times 10^{-5}$ & 135 \\
& $(10.44)$ & $(0.58)$ & $(57.09)$ & $(3.43)$ & & \\
$\boldsymbol{T C B}$ & $8.69 \pm 0.43$ & 0.60 & $48.72 \pm 1.47$ & $2.53 \pm 0.09$ & $4.6 \times 10^{-5}$ & 125 \\
& $(8.89)$ & $(0.62)$ & $(48.56)$ & $(2.66)$ & & \\
$\boldsymbol{D C B}: \boldsymbol{C F}$ & $11.62 \pm 0.72$ & 0.54 & $53.18 \pm 1.88$ & $3.28 \pm 0.25$ & $2.0 \times 10^{-5}$ & 102 \\
& $(12.73)$ & $(0.54)$ & $(53.92)$ & $(3.67)$ & &
\end{tabular}

The impact of solvent on device performance is readily apparent: $\mathrm{J}_{\mathrm{sc}}$ increases with the solvent sequence $\mathrm{CF}$ to $\mathrm{CB}$ to $\mathrm{DCB}$, yet a significant drop in $\mathrm{J}_{\mathrm{sc}}$ is observed with TCB $(\sim 10.5$ $\mathrm{mA} / \mathrm{cm}^{2}$ for DCB processed devices vs. $\sim 8.7 \mathrm{~mA} / \mathrm{cm}^{2}$ those using TCB). Film thickness $(\sim 160 \mathrm{~nm})$, as determined using profilometry (Figure S1) was the same for all devices investigated here. The absence of a C-Cl stretch at $600-800 \mathrm{~cm}^{-1}$ in the FT-IR spectra of coated films confirmed that solvent was essentially absent (Figure S2), and thus residual solvent is not a relevant factor. Open circuit voltage $\left(\mathrm{V}_{\mathrm{oc}}\right)$ was similar for devices fabricated using CF, CB and DCB, but was slightly higher for TCB processed cells. Fill factor (FF\%) and PCE\% increased with decreasing vapor pressure, but then decreased with TCB; a similar trend to that observed for $\mathrm{J}_{\mathrm{sc}}$. Hole mobility $\left(\mu_{\mathrm{H}}\right)$ (Figure S3) and exciton bandwidth (W) will be discussed later. Notably, a plateau is apparent at a vapor pressure between those of CB and DCB.

Since it was reported that spin coated P3HT:PC ${ }_{60} \mathrm{BM}$ OPV active layer performance improved when mixed high/low vapor pressure solvents were used, ${ }^{[18,29-31]}$ the viability of the same approach was investigated for blade coated active materials. When moving to a mixed solvent system, DCB:CF, with a calculated initial vapor pressure of $3 \mathrm{~mm} \mathrm{Hg}$, the $\mathrm{J}_{\mathrm{sc}}$, FF, and PCE\% improve to an average of $11.6 \mathrm{~mA} / \mathrm{cm}^{2}, 53.2 \%$, and $3.3 \%$ respectively, with PCE 
reaching a high of $3.7 \%$. Though small, this improvement in average device efficiency using a mixed solvent system relative to a single solvent is evident in Figure 2. While the statistical variation for the mixed solvent results is a larger than that for single solvents, some of the cells exhibited higher PCEs.

The results presented in Figure 2 are in concert with earlier spin coating investigations and demonstrate that a combination of low and high vapor pressure solvents may advantageously change/adjust the active layer composition. In the mixed solvent approach, the higher vapor pressure/lower BP solvent evaporates first and, thus, the conditions associated with active layer solidification are optimized. ${ }^{[32]}$ In the case of the lower vapor pressure solvents, increased drying time facilitates the degree to which self-organization within the films can change to more closely match the optimum $\mathrm{P} 3 \mathrm{HT}: \mathrm{PC}_{60} \mathrm{BM}$ morphology. ${ }^{[33]}$ However, longer drying times in and of themselves, do not correlate with improved morphology and device efficiency, rather, there is a finite drying time window which allows for development of an optimum nanoscale morphology leading to enhanced performance.

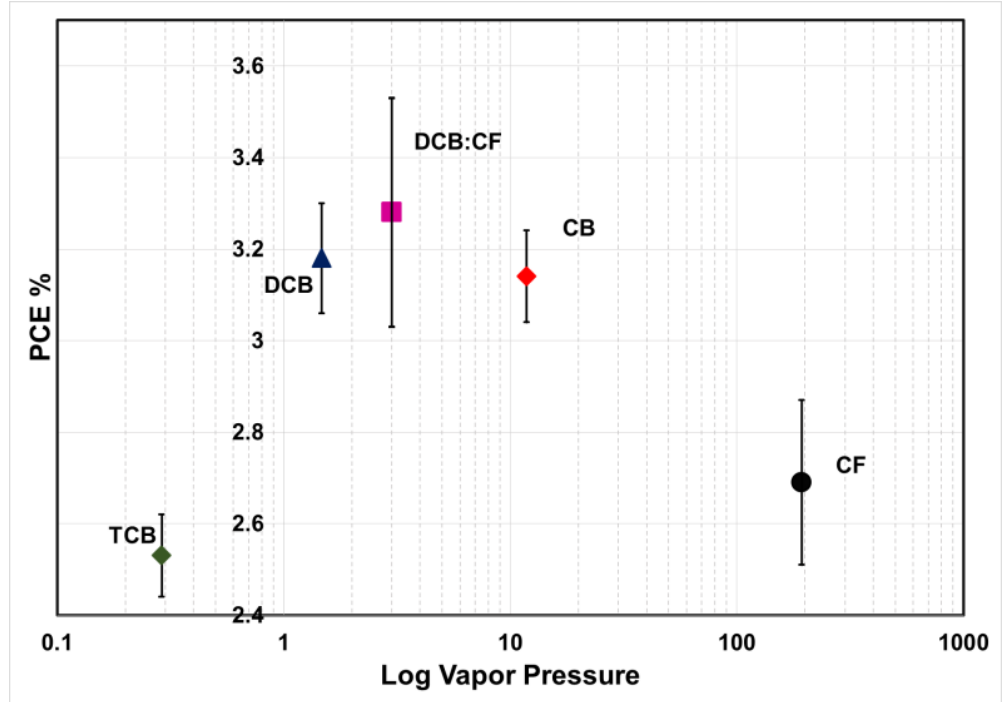

Figure 2. Influence of initial vapor pressure of P3HT:PCBM solution on blade coated solar cell device performance. The vapor pressure of the mixed solvent DCB:CF (X:Y) was calculated to be $3 \mathrm{~mm} \mathrm{Hg}$ (see Experimental Section) in order to investigate both mixed solvents and the vapor pressure regime between 1 and $10 \mathrm{mmHg}$. 
While the magnitude of the PCE's measured in DCB, CB, and DCB:CF are shown to be statistically similar, the values observed for the mixed solvent shows a larger standard deviation. In the mixed solvent, it is hypothesized that CF rapidly evaporates from the solvent
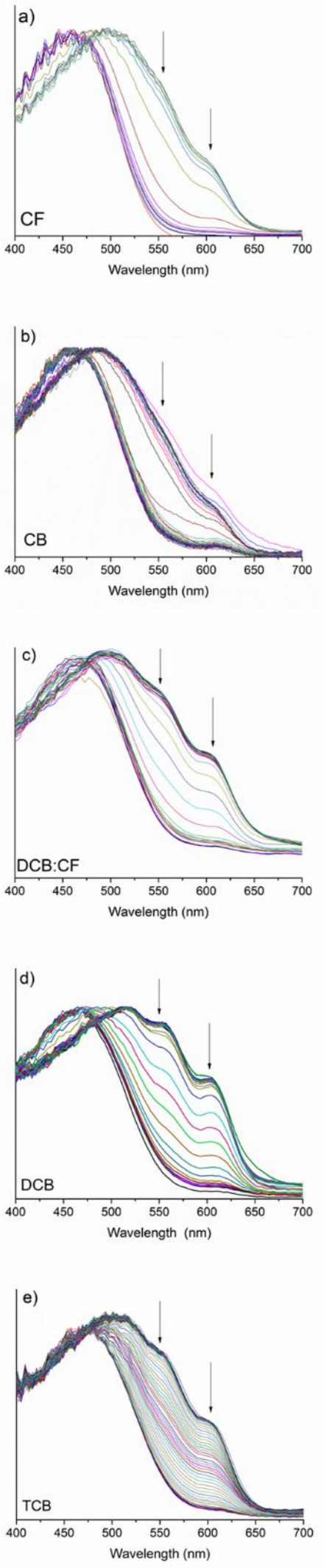

blend leaving behind DCB. The fast mass transfer process leads to evaporative cooling which will lower the temperature of the remaining solution. Evaporative cooling has been shown to induce controlled morphological features in non-conjugated polymer films. ${ }^{[34,35]}$ Given that these experiments were performed in an ambient environment, where temperature and room air flow were not tightly controlled, it is not surprising that DCB-CF which has low and high vapor pressure components exhibits a larger statistical deviation.

\subsection{In-Situ UV-vis Absorbtion of P3HT:PCBM Blade Coated Films}

In order to gain fundamental insight into how single solvents, and mixed solvents, affect the dynamically developing photovoltaic properties described earlier, an in-situ UV-vis blade coater system, built in house, was used to explore the solidification process of P3HT:PCBM as illustrated in Figure 3 where the spectra are arranged in order of decreasing initial vapor pressure (a-e). Qualitatively, it is evident that as vapor

Figure 3. In-situ UV-vis absorbance spectra of blade coated P3HT:PCBM films. Spectra are arranged in order of highest initial vapor pressure (a) to lowest initial vapor pressure (e). The arrows at $605 \mathrm{~nm}$ and $550 \mathrm{~nm}$ demonstrate the development of the $\mathrm{A}_{0-0}$ and $\mathrm{A}_{0-1}$ peaks respectively. 
pressure decreases, the development of the $A_{0-0}$ and $A_{0-1}$ peaks, at $\sim 605$ and $\sim 550 \mathrm{~nm}$ respectively, are more pronounced as indicated by the arrows. The band at $\sim 520 \mathrm{~nm}$ present in films prepared from all five solvents is due to the $\pi-\pi^{*}$ transition, while the bands at $\sim 550$ and $\sim 605 \mathrm{~nm}$ are vibronic features indicative of a high degree of molecular ordering which takes place through interchain interactions. ${ }^{[33,36]}$ Films coated from $\mathrm{CF}$ and $\mathrm{CB}$ show weak shoulder features at $605 \mathrm{~nm}$, while for films prepared from DCB, TCB, and DCB:CF, the $\sim 605 \mathrm{~nm}$ absorbance is significantly more pronounced suggesting that decreased vapor pressure facilitates an increased level of interchain interactions. ${ }^{[37]}$

The drying curves which monitor $\lambda_{\max }$ of the solidifying film as a function of time for each solvent employed here are shown in Figure 4. There are three distinct regions in these curves, to the left of the sigmoidal curve onset would be solution on substrate, where the onset of the curve begins and then ends is the drying regime, and the solidified film is apparent to the right of the end of the drying regime. The slope of the sigmoidal curves represents evaporation rate. The slopes for $\mathrm{CF}, \mathrm{CB}, \mathrm{DCB}: \mathrm{CF}, \mathrm{DCB}$ and TCB are $0.044,0.038,0.025,0.025$, and 0.014 respectively, while the corresponding times are $18 \mathrm{~s}, 20 \mathrm{~s}, 20 \mathrm{~s}, 20 \mathrm{~s}$, and $60 \mathrm{~s}$, respectively. The trend shows that as initial vapor pressure decreases, the solidification rate

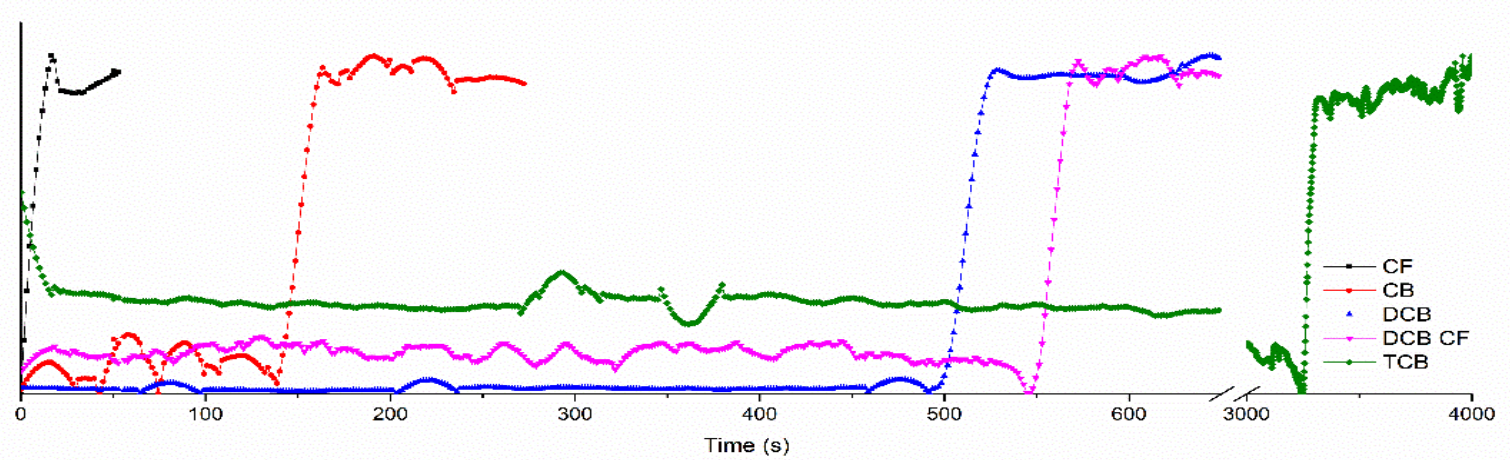

Figure 4. Drying curves of P3HT:PCBM from various solvents monitoring $\lambda$ max of the solidified film as a function of time. The sigmoid shape of each drying curve contains three regions. To the left of the onset is solution, the onset to plateau is the drying regime, and the plateau to the right is a solidified film. 
slightly decreases. The evolution of peaks at 550 and $605 \mathrm{~nm}$, corresponding to molecular order, were also examined as a function of time $(\mathbf{S 4})$, and show a similar trend to that of Figure 4. Notably, even though the solvent vapor pressures differ by orders of magnitude, the solidification rate is fairly rapid for all solvents. Interestingly, the short solidification time seen in all five solvents was also observed by others. ${ }^{[20,38]}$ Wang et al. also demonstrated similar results using in-situ ellipsometry, where the extinction coefficient of the vibronic peaks at $\lambda_{\max }, 550 \mathrm{~nm}$, and $605 \mathrm{~nm}$ of P3HT:PCBM films, cast from CB and TCB, were monitored as a function of time. For both solvents, three distinct regions corresponding to a wet film, in which the absorbtion profile is similar to that of the polymer in solution, a crystillization regime, and solidifed regime were also identified. ${ }^{[38]}$ TCB, with an initial vapor pressure of $0.29 \mathrm{mmHg}$, exhibits the longest drying time $(60 \mathrm{~s})$, while all other solvent systems have drying times of $\sim 20$ seconds. The development of the P3HT absorption bands associated with aggregation is not seen until the onset of solidification. At the conclusion of the drying regime, and the solidification curve plateaus, no further morphology development is detected by UV-vis. Thus, depending on the solvent and evaporation conditions, the bulk heterojunction morphology develops in a span of seconds up to perhaps a few minutes, in this critical regime. Since the solidification regime defines solid state film morphology, insight into this dynamic regime is vital for process optimization and control. Similar observations were presented by Schabel \& co-workers, who also found that slow drying of P3HT:PCBM led to improved crystallization, improved $\pi-\pi$ stacking and reduced series resistance. ${ }^{[39]}$

\subsection{Quantitative Analysis by UV-vis spectroscopy}

Using a modified equation developed by Neher et al, and first proposed by Spano, a quantitative picture of P3HT:PCBM films can be developed from UV-vis spectroscopic data

via Equation 1. ${ }^{[40,41]}$ This UV-vis spectral analysis was coupled with space charge limited 
current (SCLC) hole mobility measurements using a modified Mott-Gurney equation, Equation 2. ${ }^{[42]}$

Equation 1: $\quad A(E) \propto \sum_{m=0}\left(\frac{S^{m}}{m !}\right) \times\left(1-\frac{W e^{-s}}{2 E_{p}} \sum_{n \neq m} \frac{S^{n}}{n ! n-(m)}\right)^{2} \times \exp \left(\frac{\left(E-E_{0-0}-m E_{p}-0.5 W S^{m} e^{-S}\right)^{2}}{2 \sigma^{2}}\right)$

Equation 2: $\quad J_{S C L}=\frac{9}{8} \varepsilon_{0} \varepsilon_{r} \mu \frac{V_{\text {in }}^{2}}{L^{3}} \exp \left(\frac{0.89 \beta}{\sqrt{L}} \sqrt{V}\right)$
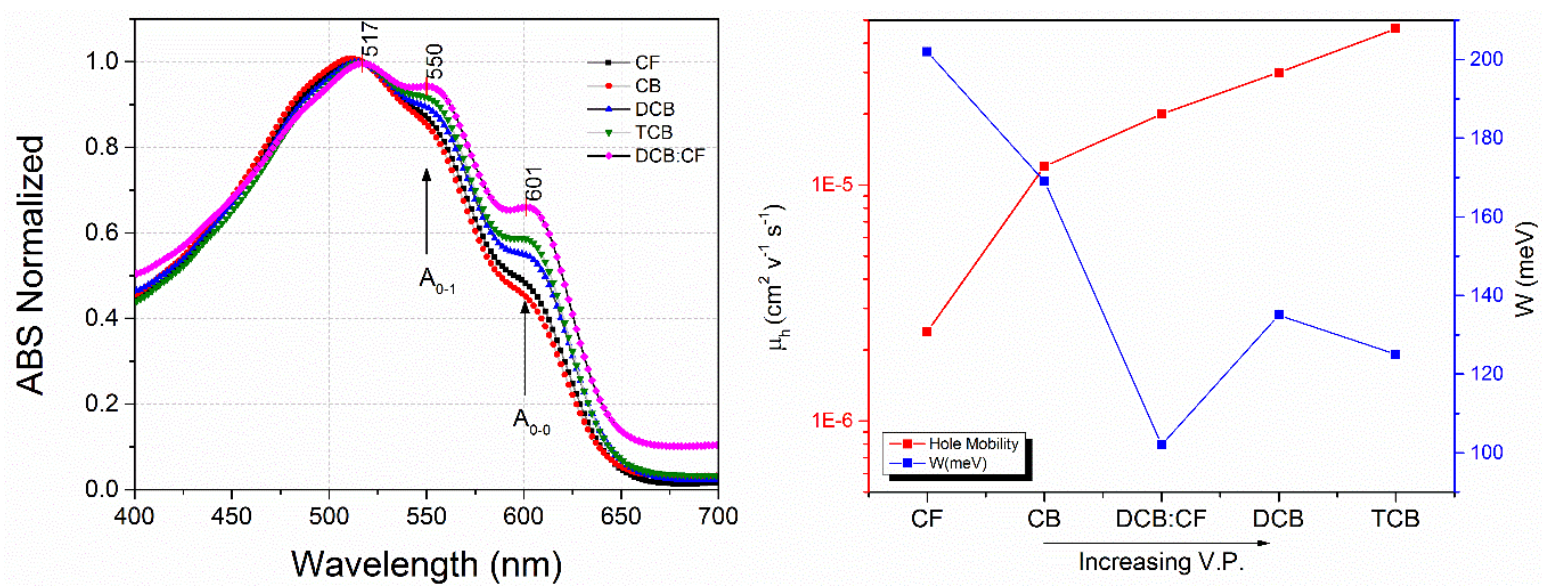

Figure 5. Absorbance spectra (a) of annealed blade coated P3HT:PCBM films. SCLC hole mobility (b) and exciton bandwidth (W).

Using the UV-vis absorption spectra of the annealed P3HT:PCBM films coated from the different solvents, the exciton bandwidth (W) was calculated from fitting of Equation 1 (Figure S5). Previously, it was shown that $\mathrm{W}$ correlates with polymer backbone planarity and conjugation length: a smaller value of $\mathrm{W}$ signifies increased ordering within the polymer film. In turn, increased ordering has been shown to correlate with improved mobility for P3HT. ${ }^{[40]}$ Figure 5 shows that as the solvent vapor pressure increases (lower boiling point), there is a decrease in $\mathrm{W}$ and simultaneously, an increase in hole mobility. CF shows the highest $\mathrm{W}(202 \mathrm{meV})$ and lowest hole mobility $\left(2.4 \times 10^{-6} \mathrm{~cm}^{2} \mathrm{~V}^{-1} \mathrm{~s}^{-1}\right)$. Interestingly, the mixed solvent, DCB:CF, exhibited the lowest W, $102 \mathrm{meV}$, suggesting that improved polymer order can be achieved using mixed solvents to tune the vapor pressure, which also impacts the overall conditions surrounding the developing film. As noted above, evaporative cooling during the film deposition process using DCB:CF is likely to occur, effecting a change in 
system temperature during solidfication. In turn, temperature may be expected to have significant impact on the resulting BHJ morphology. For instance, the solubility of a given polymer in any given solvent is thermodynamically controlled and will be affected by temperature. ${ }^{[34,35]}$ In the present case, evaporative cooling will lower the system temperature, thereby decreasing solute solubility. The dynamic changes that take place during solvent evaporation, particularly evaporation of a mixed solvent system where the components have significantly different vapor pressures, will impact the overall morphology of the solidifying film.

\subsection{Incident Photon to Charge Carrier Efficiency (IPCE)}

Figure 6 depicts the measured incident photon to current efficiency (IPCE) in the range of 300-700nm. Integration of the IPCE curves matches the experimentally determined $\mathbf{J}_{\mathrm{sc}}$ values (Figure S6) to within 7\% difference.

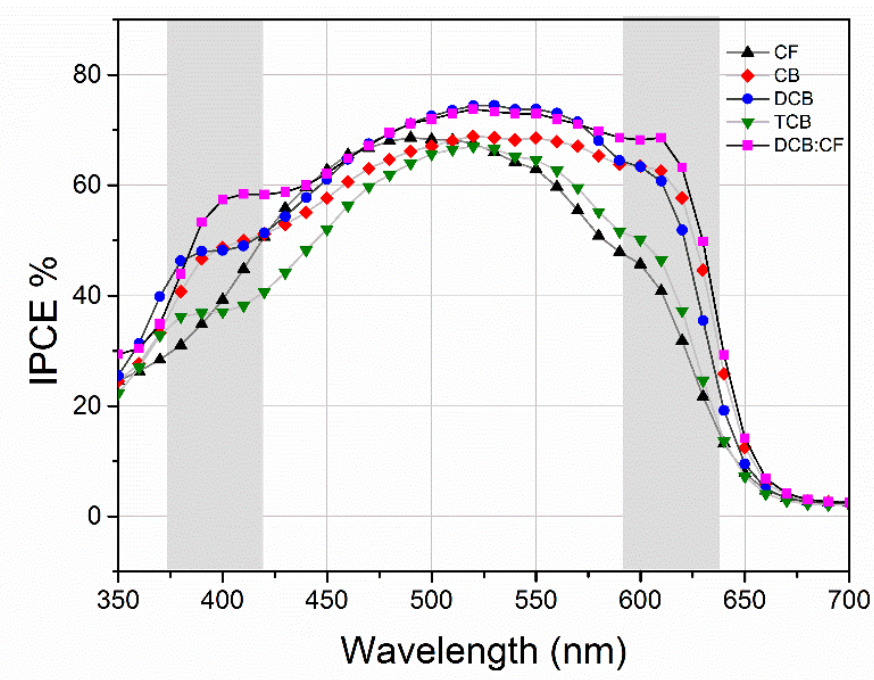

Figure 6. IPCE of devices fabricated with a blade coated $\mathrm{P} 3 \mathrm{HT}: \mathrm{PC}_{60} \mathrm{BM}$ active layer.

Examination of Figure 6 reveals the presence of pronounced shoulders in the range of 375$425 \mathrm{~nm}$ and $575-625 \mathrm{~nm}$ for the devices fabricated with the active layer/low vapor pressure solvent (CB, DCB and TCB) systems. These peaks are not as developed in films obtained from CF. Presumably, the lower vapor pressure solvents facilitate P3HT:PCBM phase 
separation into more defined domains of polymer and fullerene simply because of the timespan for solvent evaporation. While the polymer:fullerene blend is well mixed in $\mathrm{CF}$, the film dries rapidly with insufficient time for an optimized interpenetrating bulk heterojunction network to develop. Furthermore, upon examination of the mixed solvent system, the shoulders at 390 and $600 \mathrm{~nm}$ are significantly more developed explaining the increased $\mathbf{J}_{\mathrm{sc}}$ as compared to the single solvents systems. This result re-enforces the contention that solvent vapor pressure, and thus the rate with which the solvent evaporates from the blade coated active layer, is a key variable that must be controlled in order to achieve high efficiency devices through enhancing $\mathbf{J}_{\mathrm{sc}}$.

Furthermore, there is a difference in the $\lambda_{\max }$ as determined from the ICPE amongst the different P3HT:PCBM blade coated films. That obtained from CF exhibits a $\lambda_{\max }$ at $\sim 490$ $\mathrm{nm}$, while use of CB and TCB afford films with a $\lambda_{\max }$ at $\sim 520 \mathrm{~nm}$, and DCB, DCB:CF lead to a broadening of the IPCE spectra in which a clear $\lambda_{\max }$ is not discernable.. Thus, use of high vapor pressure solvents appears to facilitate development of aggregation bands at about 610 $\mathrm{nm}$, and red shift and broaden the IPCE spectrum. Notably, addition of a high vapor pressure component to DCB accentuates these effects.

\subsection{Surface Morphology Explored Through Atomic Force Microscopy}

Tapping mode AFM was used to evaluate the blade coated $\mathrm{P} 3 \mathrm{HT}: \mathrm{PC}_{60} \mathrm{BM}$ thin-film surface topographies. Height and phase images are presented in Figure 7. 


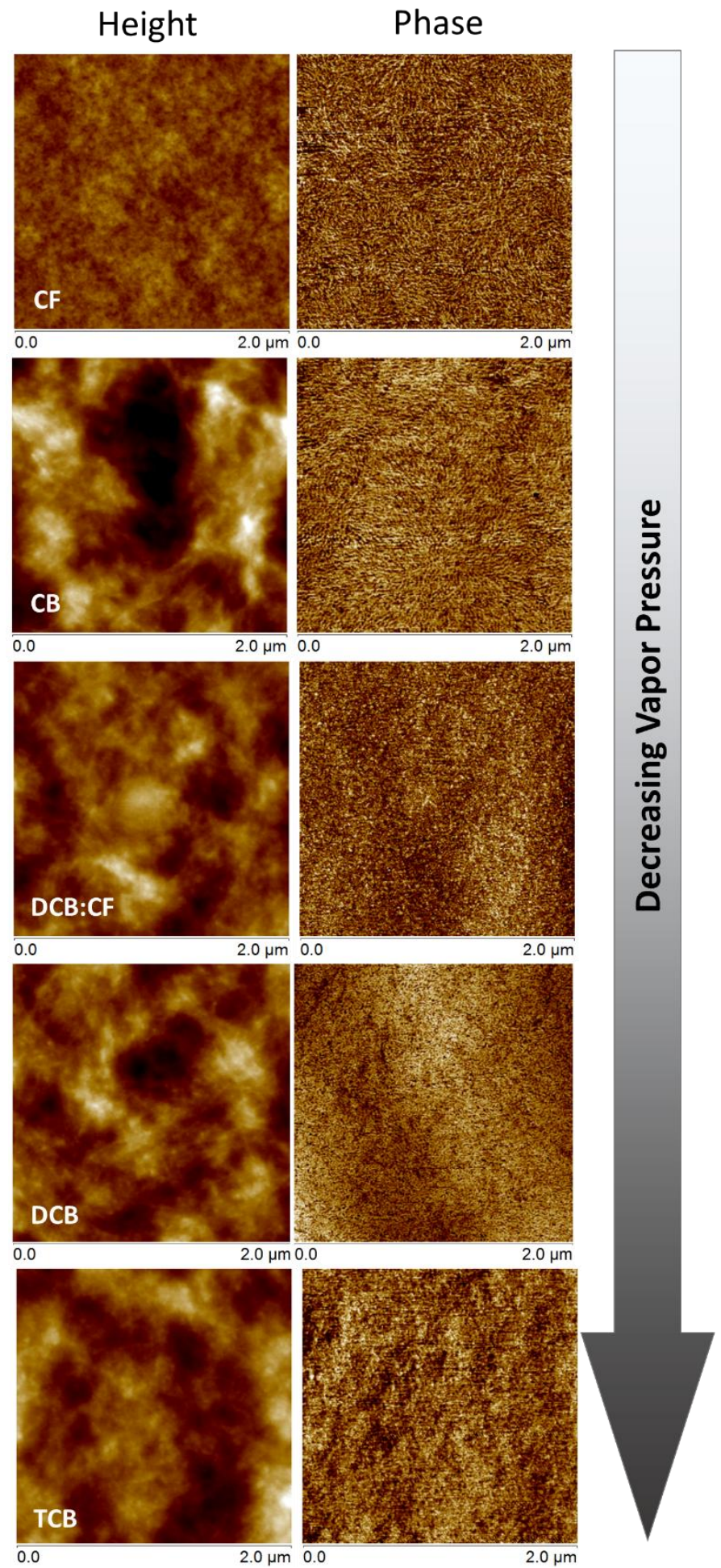

Figure 7. AFM tapping mode height (left) and phase (right) images of $\mathrm{P} 3 \mathrm{HT}: \mathrm{PC}_{60} \mathrm{BM}$ thinfilms obtained using $\mathrm{CF}, \mathrm{CB}, \mathrm{DCB}: \mathrm{CF}, \mathrm{DCB}$ and $\mathrm{TCB}$ as the processing solvent.

From examination of Figure 7, blade coating of the active layer blend from the solvent systems investigated here has as a pounced effect on film roughness. All images are $2 \mu \mathrm{m} x$ 
$2 \mu \mathrm{m}$ with a light to dark, peak to valley, height sensitivity of $\pm 25 \mathrm{~nm}$. The films coated from CF have a RMS roughness of only about $1 \mathrm{~nm}$, while CB, DCB:CF, DCB and TCB films show RMS roughness values of $9.5,5.4,5.9$, and $6.5 \mathrm{~nm}$ respectively. The smooth film features present in the devices fabricated from $\mathrm{CF}$ are attributed to the high vapor pressure of the solvent: with $\mathrm{CF}$ as the deposition medium, the film effectively solidifies and dries immediately upon coating. The fast drying process does not allow for sufficient time for the P3HT:PC ${ }_{60} \mathrm{BM}$ blend to phase separate, thus the resultant film is smoother than those prepared from lower vapor pressure solvents. ${ }^{[43,44]}$ The increased roughness apparent in films prepared from the lower vapor pressure solvents is ascribed to a higher degree of P3HT selforganization. $^{[17,20]}$

Phase images of the blade coated active layers are shown in Figure 7 on the right. The films obtained from $\mathrm{CF}$ and $\mathrm{CB}$ are quite comparable. Both present a granular-like phase structure where small fibril-like components can be discerned. These small fibrillar structures are not apparent in P3HT: $\mathrm{PC}_{60} \mathrm{BM}$ films prepared from either DCB or TCB. The DCB and TCB films are similar, with no clear, well defined structure. The lower vapor pressure DCB and TCB solvents evaporate more slowly from the solidifying active layer and thereby provide time for development of a much more finely grained nanoscale morphology that was not discerned. The phase image for the blend deposited from the mixed solvent shows no definitive characteristics.

\section{Conclusion}

The impact of chlorinated solvent characteristics, specifically the effect of vapor pressure, on the performance of inverted solar cells prepared with blade coated $\mathrm{P} 3 \mathrm{HT}: \mathrm{PC}_{60} \mathrm{BM}$ active layers has been investigated. From the single solvent systems examined here, DCB provides a morphology that facilitates optimum device performance. However, a mixed solvent system having a combination of high and low vapor pressure solvents formed a more advantageous 
composition allowing for an optimum time for solidification of the film and formation of a nanoscale morphology conducive to charge separation and transport, thereby maximizing OPV device performance. These results correspond well with other studied conjugated polymer systems. For instance, Russell \& co-workers demonstrated that solvent mixing of CF and DCB proved advantageous for the low bandgap polymer pDPP and $\mathrm{PC}_{71} \mathrm{BM}^{[45]}$ The evaporation of CF induces crystallization of pDPP due to the poor solvent quality interactions with the remaining solvent, $\mathrm{DCB}$, while $\mathrm{DCB}$ aids to solubilize $\mathrm{PC}_{71} \mathrm{BM}$. As $\mathrm{DCB}$ is a poor solvent for this polymer, it aids in crystallization with solidification. At the same time, it is well known that DCB is a good solvent for PCBM, thus there for there is finer phase separation between the crystallized polymer and fullerene in the blend.

While $\mathrm{CF}, \mathrm{CB}, \mathrm{DCB}$, and TCB, are known to be good solvents for $\mathrm{P} 3 \mathrm{HT}: \mathrm{PC}_{60} \mathrm{BM}$, when used as solvents for blade coating the active layer films, resultant thin-film morphologies and ultimate OPV device characteristics markedly differ. OPV performance was demonstrated to improve for devices prepared with $\mathrm{P} 3 \mathrm{HT}: \mathrm{PC}_{60} \mathrm{BM}$ blends processed with lower vapor pressure solvents, but only up to a threshold value. After crossing that threshold, performance decreases dramatically as seen with DCB and TCB. Solvent mixing will likely be pivotal to achieve optimum device efficiencies and could also be beneficial as a method for fine tuning surface energies to obtain uniform blade coated thin films for OPV devices. A key finding is that bulk heterojunction morphology development occurs during a short period of time in the film solidification regime. As demonstrated by in-situ UV-vis spectroscopic analysis, polymer packing occurs during a short, defined point in time when solvent evaporation occurs rapidly. As ascertained from the results associated with the mixed DCB:CF solvent system, temperature and thus system thermodynamics and phase behavior are also important in defining the ultimate film morphology which plays a significant role in solar cell performance. 


\section{Experimental Section}

Materials: $\mathrm{PC}_{60} \mathrm{BM}$ was purchased from Nano-C. Poly(3-hexylthiophene-2,5-diyl) (P3HT) Plexcore OS $2100 M_{n}$ 54,000-75,000 99.995\% trace metal basis was purchased from Sigma Aldrich. All other materials were purchased from Sigma Aldrich and used as is unless otherwise noted.

Solubility of P3HT: P3HT was dissolved in four solvents; chloroform, chlorobenzene, orthodichlorobenzene and trichlorobenzene. Concentration of all solutions was $40 \mathrm{mg} \mathrm{mL} \mathrm{m}^{-1}$. Solutions were placed on a hot plate set to $70^{\circ} \mathrm{C}$ and allowed to stir for 24 hours. All solutions were then removed from the hotplate and allowed to cool to room temperature. After, all solutions were individually filtered through a $0.45 \mu \mathrm{m}$ PTFE filter using a glass syringe into separate vials. Next, a known amount of the filtered solution was taken and placed into a preweighed vial. All vials were then placed in a vacuum oven with a temperature at $60^{\circ} \mathrm{C}$ and pressure of $10^{-1}$ mbar for 8 hours. Trichlorobenzene was placed on a hotplate set to $300^{\circ} \mathrm{C}$ for another hour to insure all the solvent was removed. All four vials were then re-weighed and the mass difference was used to calculate solubility.

Solar cell fabrication: Patterned ITO on glass was ultra-sonicated in sodium dodecyl sulfate in water followed by acetone and then isopropanol. ITO was blown dry with Ar gas then UV ozone treated. $\mathrm{ZnO}$ sol-gel, made from $0.32 \mathrm{~g}$ of $\mathrm{Zn}$ acetate dehydrate in $1920 \mu \mathrm{L}$ of 2methoxyethanol and $80 \mu \mathrm{L}$ of ethanol amine, was spin coated on the ITO at $800 \mathrm{rpm}$ for 50 sec. The $\mathrm{ZnO}$ thin film was annealed in air at $400^{\circ} \mathrm{C}$ for 5 minutes. Solutions of P3HT and $\mathrm{PC}_{60} \mathrm{BM}$ in a 1:0.8 wt ratio, in concentrations of $33 \mathrm{mg} \mathrm{mL}^{-1}$ in chloroform, $38 \mathrm{mg} \mathrm{mL}^{-1}$ in chlorobenzene, $26 \mathrm{mg} \mathrm{mL}^{-1}$ in dichlorobenzene, $20 \mathrm{mg} \mathrm{mL}^{-1}$ in trichlorobenzene, and $26 \mathrm{mg}$ $\mathrm{mL}^{-1} \mathrm{DCB}: \mathrm{CF}$ were made and allowed to stir for 48 hours at $70^{\circ} \mathrm{C}$ in an Ar filled glove box. All solutions were then blade coated onto the $\mathrm{ZnO}$ film at $5 \mathrm{~mm} \mathrm{sec}^{-1}$ with a $15 \mu \mathrm{m}$ blade gap in air using a Zehntner ZAA 2300 with a ZUA 2000 blade in air. The solvent mixture was calculated to be $3 \mathrm{~mm} \mathrm{Hg}$ vapor pressure using Raoult's Law. The devices were left to dry for 12 hours in air and then transferred to an Ar filed glovebox where they were annealed at $140^{\circ} \mathrm{C}$ for 35 minutes. $4 \mathrm{~nm}$ of molybdenum oxide and $100 \mathrm{~nm}$ of $\mathrm{Ag}$ was thermally evaporated onto the devices through a mask at $10^{-6}$ mbar as the electrodes. Active area of devices is $0.07 \mathrm{~cm}^{2}$.

SCLC hole mobility devices: ITO was cleaned the same way as described in solar cell fabriactaion. Following cleaning, PEDOT:PSS (Al 4083) was spun coat at $5000 \mathrm{rpm}$ for 60 seconds and dried in air at $120^{\circ} \mathrm{C}$ for 20 minutes. The active layer was then blade coated on, 
and devices were annealed in the same fashion described for solar cell fabrication. $80 \mathrm{~nm}$ of Au contacts were thermally evaporated on.

Characterization: A Newport ABB solar simulator coupled with a Keithley SMU for measuring device efficiency under standard AM 1.5 conditions calibrated to $100 \mathrm{~mW} / \mathrm{cm}^{2}$ using a reference solar cell was used to collect J-V. A Newport EQE/IPCE setup with a white light source and a monochromator to allow for external quantum efficiency and incident photon-to-current efficiency measurements was used to collect IPCE. UV-vis spectra were obtained using a Varian Cary 5000 UV/VIS/NIR. Thin film characterization was performed with a Bruker stylus profilometer. AFM was gathered with a Bruker Atomic Force Microscope (Dimension icon), which can operate under standard tapping mode (using a Bruker Tap 150 cantilever) to gather height and phase information. A Perkin Elmer Spectrum One FT-IR was used for IR measurements.

\section{Acknowledgements}

This work was supported through a grant from the Office of Naval Research N00014-14-10173. We appreciate the input from Mr. James Ponder in this work.

Received: ((will be filled in by the editorial staff))

Revised: ((will be filled in by the editorial staff)) Published online: ((will be filled in by the editorial staff))

\section{References}

[1]. International Energy Outlook 2013. Release Date: July 25, 2013. Report Number: DOE/EIA-0484(2013)

[2]. A.K.K. Kyaw, D.H. Wang, D. Wynands, J. Zhang, T.Q. Nguyen, G.C. Bazan, A.J. Heeger, Nano Lett., 2013, 13, 3796.

[3]. K. Sun, Z. Xiao, S. Lu, W. Zajaczkowski, W. Pisula, E. Hanssen, J. M. White, R. M. Williamson, J. Subbiah, J. Ouyang, A. B. Holmes, W. W.H. Wong, D. J. Jones. Nat. Commun., 2015, 6, 6013.

[4].Z. He, C. Zhong, S. Su, M. Xu, H. Wu, Y. Cao, Nat. Photonics, 2012, 6, 593.

[5].Z. He, C. Zhong, X. Huang, W.-Y. Wong, H. Wu, L. Chen, S. Su, Y. Cao, Adv. Mater., 2011, 23, 4636.

[6].P.M. Beaujuge, J.M.J. Fréchet. J. Am. Chem. Soc., 2011, 133 (50), 20009.

[7]. F. Krebs, Sol. Energy Mater. Sol. Cells, 2009, 93, 394.

[8]. W. Nie, R. Coffin, J. Liu, Y. Li, E. Peterson, C. MacNeill, R. Noftle, D. Carroll, Appl. Phys. Lett., 2012, 100, 083301. 
[9]. J.-W. Kang, Y.-J. Kang, S. Jung, M. Song, D.-G. Kim, C. S. Kim, S. H. Kim, Sol. Energy Mater. Sol. Cells, 2012, 103, 76.

[10]. J.-S. Yu, I. Kim, J.-S. Kim, J. Jo, T.T. Larsen-Olsen, R.R. Søndergaard, M. Hosel, D. Angmo, M. Jørgensen, F.C. Krebs, Nanoscale 2012, 4, 6032.

[11]. S.H. Eom, H. Park, S.H. Mujawar, S.C. Yoon, S.-S. Kim, S.-I. Na, S.-J. Kang, D. Khim, D.-Y. Kim, S.-H. Lee, Org. Electron., 2010, 11, 1516.

[12]. C.N. Hoth, P. Schilinsky, S.A. Choulis, C.J. Brabec, Nano lett., 2008, 8(9), 806.

[13]. P. Schilinsky, C. Waldauf, C.J. Brabec, Adv. Funct. Mater., 2006, 16, 1669.

[14]. J.-H. Chang, Y.-H. Chen, H.-W. Lin, Y.-T. Lin, H.-F. Meng, E.-C. Chen, Org. Electron., 2012, 13, 705.

[15]. S.-L. Lim, E.-C. Chen, C.-Y. Chen, K.-H. Ong, Z.-K. Chen, H.-F. Meng, Sol. Energy Mater. Sol. Cells, 2012, 107, 292.

[16]. R. Mens, F. Demir, G. Van Assche, B. Van Mele, D. Vanderzande, P. Adriaensens, J. Polym. Sci. A Polym. Chem., 2012, 50, 1037.

[17]. Y.-H. Chang, S.-R. Tseng, C.-Y. Chen, H.-F. Meng, E.-C. Chen, S.-F. Horng, C.-S. Hsu, Org. Electron., 2009, 10, 741.

[18]. Y.-R. Hong, P.-K. Chen, J.-C. Wang, M.-K. Lee, S.-F. Horng, H.-F. Meng, Sol. Energy Mater. Sol. Cells, 2014, 120, 197.

[19]. N. Li, D. Baran, G.D. Spyropoulos, H. Zhang, S. Berny, M. Turbiez, T. Ameri, F.C. Krebs, C.J. Brabec, Adv. Energy Mater., 2014, doi: 10.1002/aenm.201400084.

[20]. N. Shin, L.J. Richter, A.A. Herzing, R.J. Kline, D.M. DeLongchamp, Adv. Energy Mater., 2013, 3, 938.

[21]. C.-Y. Chen, H.-W. Chang, Y.-F. Chang, B.-J. Chang, Y.-S. Lin, P.-S. Jian, H.-C. Yeh, H.-T. Chien, E.-C. Chen, Y.-C. Chao, H.-F. Meng, H.-W. Zan, H.-W. Lin, S.-F. Horng, Y.-J. Cheng, F.-W. Yen, I.-F. Lin, H.-Y. Yang, K.-J. Huang, M.-R. Tseng, J. Appl. Phys., 2011, 110, 094501.

[22]. M. Abdelsamie, K. Zhao, M.R. Niazi, K.W. Chou, A. Amassian, J. Mater. Chem. C, 2013, 2, 3373.

[23]. K.W. Chou, B. Yan, R. Li, E.Q. Li, K. Zhao, D.H. Anjum, S. Alvarez, R. Gassaway, A. Biocca, S.T. Thoroddsen, A. Hexemer, A. Amassian, Adv. Mater., 2013, 25, 1923.

[24]. M. T. Dang, G. Wantz, H. Bejbouji, M. Urien, O. J. Dautel, L. Vignau, L. Hirsch, Sol. Energy Mater. Sol. Cells, 2011, 95, 3408.

[25]. F. Machui, S. Langner, X. Zhu, S. Abbott, C. J. Brabec, Sol. Energy Mater. Sol. Cells, 2012, 100, 138.

[26]. D.T. Duong, B. Walker, J. Lin, C. Kim, J. Love, B. Purushothaman, J.E. Anthony, T.-Q. Nguyen, J. Polym. Sci. B Polym. Phys., 2012, 50, 1405.

[27]. S. K. Hau, H.-L. Yip, N. S. Baek, J. Zou, K. O’Malley, A. K.-Y. Jen, Appl. Phys. Lett., 2008, 92, 253301.

[28]. E.J. Luber, J.M. Buriak, ACS Nano, 2013, 7(6), 4708.

[29]. S.-H. Jin, B. Vijaya Kumar Naidu, H.-S. Jeon, S.-M. Park, J.-S. Park, S. C. Kim, J. W. Lee, Y.-S. Gal, Sol. Energy Mater. Sol. Cells, 2007, 91, 1187.

[30]. K. Kawano, J. Sakai, M. Yahiro, C. Adachi, Sol. Energy Mater. Sol. Cells, 2009, 93, 514.

[31]. M.N. Yusli, T. Way Yun, K. Sulaiman, Mater. Lett., 2009, 63, 2691.

[32]. Y. Yao, J. Hou, Z. Xu, G. Li, Y. Yang, Adv. Funct. Mater., 2008, 18, 1783.

[33]. G. Li, V. Shrotriya, J. S. Huang, Y. Yao, T. Moriarty, K. Emery, Y. Yang, Nat. Mater., 2005, 4, 864.

[34]. Zhang, A., Du, C., Bai, H., Wang, Y., Wang, J., \& Li, L. ACS applied materials \& interfaces, 2014, 6(11), 8921-8927. 
[35]. Srinivasarao, M., Collings, D., Philips, A., \& Patel, S. Three-dimensionally ordered array of air bubbles in a polymer film. Science, 2001, 292(5514).

[36]. T.-F. Guo, T.-C. Wen, G. Pakhomov, X.-G. Chin, S.-H. Liou, P.-H. Yeh, C.-H. Yang, Thin Solid Films, 2008, 516, 3138.

[37]. Y. Zhao, Z. Xie, Y. Qu, Y. Geng, L. Wang, Appl. Phys. Lett., 2007, 90, 043504.

[38]. T. Wang, A.D. Dunbar, P.A. Staniec, A.J. Pearson, P.E. Hopkinson, J.E.

MacDonald, D.G. Lidzey, Soft Matter, 2010, 6(17), 4128.

[39]. B. Schmidt-Hansberg , M. Sanyal , M. F. G. Klein , M. Pfaff ,N. Schnabel , S. Jaiser,

A. Vorobiev , E. Müller, A. Colsmann, P.Scharfer, D. Gerthsen , U. Lemmer , E.

Barrena, W. Schabel , ACS Nano 2011 , 5 , 8579 - 8590 .

[40]. S. T. Turner, P. Pingel, R. Steyrleuthner, E. J. W. Crossland,S. Ludwigs and D.

Neher, Adv. Funct. Mater., 2011,21, 4640.

[41]. F. C. Spano, Chem. Phys., 2006,325, 22.

[42]. N. Mott and R. Gurney, Electronic Processes in Ionic Crystals, Oxford University Press, London, 1940.

[43]. B. Schmidt-Hansberg, M.F. Klein, K. Peters, F. Buss, J. Pfeifer, S. Walheim, S., W.Schabel, J. Appl. Phys., 2009, 106(12), 124501.

[44]. T. Wang, A.D. Dunbar, P.A. Staniec, A.J. Pearson, P.E. Hopkinson, J.E.

MacDonald, D.G. Lidzey, Soft Matter, 2010, 6(17), 4128.

[45]. F. Liu, Y. Gu, C. Wang, W. Zhao, D. Chen, A.L. Briseno, \& T.P. Russell, $A d v$. Mater, 2012 24(29), 3947-3951.

The table of contents entry

Blade coating of P3HT:PCBM organic solar cells has been carried out using active layer solutions of varied initial vapor pressure. It is demonstrated that a "sweet spot" in the solution properties leads to the optimum bulk heterojunction morphology and power conversion efficiency.

\section{Keyword}

Jeff L. Hernandez, Elsa Reichmanis and John Reynolds. *

Title : Blade Coating: Vapor Pressure Effects on Organic Photovoltaics

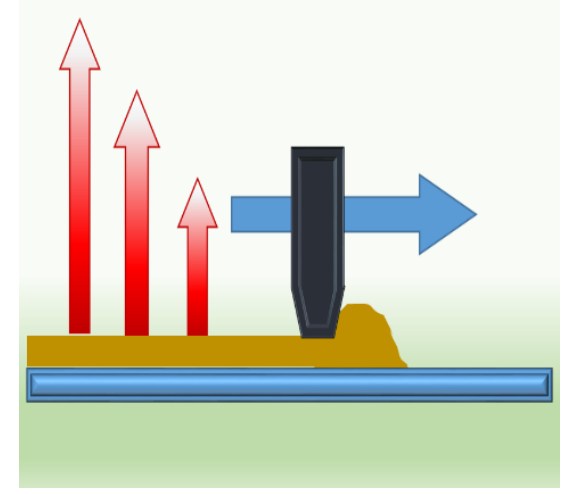

